\title{
The Effects of Acute and Chronic Immobilization Stress and Aloe vera Extract on Serum Levels of TSH, T3 and T4 in Male Rats
}

\author{
Rahim Ahmadi ${ }^{1}$; Zahra Abbasi ${ }^{1, *}$; Vahid Asgary $^{2}$ \\ ${ }^{1}$ Department of Biology, Faculty of Basic Sciences, Hamedan Branch, Islamic Azad University, Hamedan, Iran \\ ${ }^{2}$ Department of Immunology, School of medicine, Tehran University of Medical Sciences, Tehran, Iran \\ ${ }^{*}$ Corresponding author: Zahra Abbasi, Department of Biology, Faculty of Basic Sciences, Hamedan Branch, Islamic Azad University, Hamedan, IR Iran. Tel: 09126120353 E-mail: zahab- \\ basi52@gmail.com
}

Received: April 18, 2013; Accepted: October 16, 2013

\begin{abstract}
Background: Stress has different effects on the body and endocrine system.
Objectives: The main aim of this study is to determine the effects of immobilization stress and Aloe vera extract on levels of TSH, T3 or T4 in male rats.

Materials and Methods: In this experimental study, 90 male Wistar rats were randomly divided into 9 groups of control, receiving normal saline, receiving Aloe vera extract, acutely immobilized ( $8 \mathrm{~h} /$ day immobilization for 8 days), chronically immobilized ( $2 \mathrm{~h} /$ day immobilization for 21 days) acutely immobilized receiving Aloe vera extract, chronically immobilized receiving Aloe vera extract, acutely immobilized receiving normal saline and chronically immobilized receiving normal saline $(n=10)$. Blood samples were collected using cardiac puncture method and hormone levels were measured by electrochemiluminescence (ECL) method. Data were statistically analyzed and compared among groups using ANOVA.

Results: Results showed that levels of T3 and T4 were significantly increased in rats enduring acute immobilization stress compared with animals in control group $(\mathrm{P}=0.001)$. Serum $\mathrm{T} 3$ and $\mathrm{T} 4$ were significantly decreased in Aloe vera receiving rats compared with control group $(\mathrm{P}<0.05$ or $\mathrm{P}<0.01$, respectively). Level of $\mathrm{T} 3$ was significantly decreased in acutely immobilized rats receiving Aloe vera compared with control group $(\mathrm{P}=0.001)$. Level of $\mathrm{T} 3$ and $\mathrm{T} 4$ levels were significantly decreased in chronically immobilized rats receiving Aloe vera compared with control group $(\mathrm{P}<0.05)$.

Conclusions: The findings show that acute immobilization enhances levels of T3, T4 and TSH and the use of Aloe vera extract can prevent this kind of increase.
\end{abstract}

Keywords: Thyrotrophs; Immobilization; Aloe; Rats

\section{Background}

Immobilization is a kind of physiological stress which has two types of acute and chronic in different organisms and can have different effects on physiology of animals, including their growth, physiological function of hypothalamus, pituitary, adrenal and thyroid glands, particularly (1-8). On the other hand, thyroid is one of the most important endocrine glands which regulate various functions in the body (9). Thyroxin (T4) and triodothyronine (T3) are thyroid hormones that regulate various activities in the body $(10,11)$. Any disruption in normal levels of thyroid hormones can cause physiological abnormalities (9). Although thyroid disorders are widespread these days (9), the function of thyroid axis on stress has less been studied (12) and there are not enough studies on the effect of stressful factors on secretion and metabolism of thyroid hormones, and the changes of these factors on the target organ (13). Moreover, research on the effects of plant extracts in the treatment of thyroid disorders is also little (9).

There are many plants that have effects on thyroid hormone concentrations in laboratory animals (14-17). One of the plants that have been studied a lot is Aloe vera. Aloe vera is from Liliaceae family with the Persian name "Aloe bitter" which grows mainly in dry areas and belongs to the Lily family. Research on Aloe vera and other plants of this family show that the extracts from these plants have significant effects on various physiological functions such as improving heart functions, arthritic pain relief (18), glucose and cholesterol control (19), energy production, strengthening the immune system (20), curing ulcer and skin wounds, asthma, and digestive disorders $(21,22)$. There are some other studies showing the effect of Aloe vera on thyroid gland function $(9,23)$. Since in most cases, different stresses especially immobilization stress can influence thyroid function and Aloe vera have also effects on thyroid function $(9,23)$.

\section{Objectives}

This study is designed to evaluate the effects of immobilization stress along with Aloe vera extract on male rats in order to examine the effect of Aloe vera on controlling or strengthening the effects of immobilization stress on thyroid gland function.

Copyright @ 2015, Zahedan University of Medical Sciences. This is an open-access article distributed under the terms of the Creative Commons Attribution-NonCommercial 4.0 International License (http://creativecommons.org/licenses/by-nc/4.0/) which permits copy and redistribute the material just in noncommercial usages, provided the original work is properly cited. 
Ahmadi R et al.

\section{Materials and Methods}

In this experimental laboratory study, 90 Wistar male rats weighing 180 - $200 \mathrm{~g}$ were provided from Pasteur Institute of Iran. The animals were kept under natural conditions with a normal diet at temperature $22 \pm 2^{\circ} \mathrm{C}$ and a photoperiod of 12 hours darkness and 12 hours light considering the beginning of the photoperiod from 8 AM. The animals were given food and water unlimitedly. Instant food for rats was provided by Pars animal factory and all the other conditions were kept unchanged during the study (24). All experiments were conducted based on ethics related to empirical tests on animals. Animals were randomly grouped and each member of the sample was numbered and was adapted to the host.

None of the animals under study suffered from any diseases neither were they seen with any symptoms. Samples were randomly divided into 9 groups of control, receiving normal saline, receiving Aloe vera extract (orally at a dose of $625 \mathrm{mg} / \mathrm{kg}$ for 21 days), acutely immobilized ( $8 \mathrm{~h} /$ day immobilization for 8 days), chronically immobilized ( $2 \mathrm{~h}$ /day immobilization for 21 days) acutely immobilized receiving Aloe vera extract, chronically immobilized receiving Aloe vera extract, acutely immobilized receiving normal saline, and chronically immobilized receiving normal saline $(\mathrm{n}=10)$.

Aloe vera extract was administered through gavage. Briefly, Aloe vera extract was prepared according to the slightly modified method used by Chitra et al. (21). Ripe leaves of the plant were purchased from Bou-Ali-Sina herbal garden in Hamedan. After washing and removing the outer green skin, transparent parenchyma of the plant was extracted and turned into a homogeneous mixture using a blender. Then the mixture was put in a centrifuge (3500 rpm) so that the fibers are separated. After centrifugation, the separated layer was diluted with water and a $20 \%$ solution was obtained. This obtained solution was kept at temperature $4^{\circ} \mathrm{C}$. Acute immobilization stress, acute immobilization receiving Aloe vera extract and acute immobilization stress receiving normal saline groups on the 8th day of the experiment and chronic immobilization stress, chronic immobilization receiving Aloe vera extract, chronic immobilization receiving normal saline groups, a group receiving both Aloe vera extract and normal saline and control group on 20th day first were anesthetized by ether immediately after the end of the experiment and blood samples were taken from the heart. The blood samples were immediately centrifuged for 10 minutes at around $3500 \mathrm{rpm}$ to collect the serum. Then levels of TSH, T3 and T4 were measured through electro-chemiluminescence method. Hormone measurement was conducted using assay kit "Immuno tech A, Bech man coucter/REF2121". Since in the present study the only kind of stress was immobilization, a limiting system was used.

The limiting system was a special system used by BouAli-Sina University for its research activities. The system is designed so that without fastening the rat $\mathrm{s}$ feet and hands it does not have any space to move. The device also has some vents for ventilation.

In acute immobilization stress lasting for $8 \mathrm{~h} /$ day for 8 days, the animals had a 50 minutes immobilization stress and then a 10 minutes rest and feeding period and another 50 minutes immobilization stress to complete the 8 hours period. In chronic immobilization stress lasting for 2 hours every day for 21 days (2), the animals had a 50 minutes immobilization stress and then a 10 minutes rest and feeding period and another 50 minutes immobilization stress to complete the 8 hours period.

First, Kolmogorov-Smirnov was used to ensure a normal distribution of data, and then the data were analyzed through SPSS-18 and one-way ANOVA. In variance analysis, significance of differences between groups was determined using Fisher's test.

\section{Results}

Table 1 shows the levels of TSH, T3 and T4 in control groups, acute immobilization stress, and chronic immobilization stress, acute immobilization receiving normal saline and chronic immobilization receiving normal saline groups. Statistical analysis indicates that serum levels of T3 and T4 hormones in rats under acute immobilization stress compared to control group were significantly increased $(\mathrm{P}=0.01, \mathrm{P}=0.006$, respectively), but there was no significant change compared to acute immobilization stress group receiving normal saline. On the other hand, there was no significant difference between hormone levels of TSH, T3 and T4 in rats under chronic immobilization stress and control group or chronic immobilization stress receiving normal saline. There was also a significant increase in serum levels of TSH, T3 and T4 in rats under acute immobilization stress receiving normal saline compared to control (respectively $\mathrm{P}=0.015, \mathrm{P}=0.001, \mathrm{P}=0.006$ ), but the serum levels of this hormone in rats under chronic immobilization compared to rats with chronic immobilization receiving normal saline, do not show a significant difference. Additionally, the serum levels of TSH, T3 and T4 in groups receiving Aloe vera, acute immobilization stress receiving the extract and chronic immobilization receiving the extract are shown in Table 2.

As shown in Table 2, the serum levels of TSH, T3 and T4 in group receiving normal saline compared with control group was not significantly different. However, except $\mathrm{TSH}$, these hormones in the group receiving Aloe vera extract were significantly reduced comparing to control group (respectively $\mathrm{P}=0.043$ and $\mathrm{P}=0.007$ ). Moreover, in rats under acute immobilization receiving the extract compared to control group, serum level of T3 has been significantly reduced, but no significant difference was observed for serum levels of TSH and T4. There was also a significant decrease in serum T3 and T4 in chronic immobilization group that receiving the extract compared to control group (respectively $\mathrm{P}=0.021$ and $\mathrm{P}=0.012$ ). Figures 1 and 2 show changes in T3, T4 and TSH levels in different groups compared to each other and the control group. 
Ahmadi Ret al.

Table 1. Analysis of Data Hormone Concentrations of T3, T4 and TSH in Serum of Male Wistar Rats a,b

\begin{tabular}{|c|c|c|c|c|c|c|}
\hline Indexes & TSH $(\mu \mathbf{g} / \mathbf{d L})$ & P Value & T3 $(\mu \mathbf{g} / \mathbf{d L})$ & PValue & $\mathbf{T 4}(\mu \mathbf{g} / \mathbf{d L})$ & P Value \\
\hline Control & $0.01 \pm 0.001$ & - & $0.58 \pm 73.2$ & - & $3.65 \pm 0.20$ & - \\
\hline Acute immobilization stress + normal saline & $0.014 \pm 0.001$ & NS & $82.92 \pm 0.99$ & $>0.01$ & $5.20 \pm 0.08$ & $>0.01$ \\
\hline Chronic immobilization stress + normal saline & $0.009 \pm 0.001$ & NS & $73.26 \pm 0.40$ & NS & $3.44 \pm 0.05$ & NS \\
\hline Acute immobilization stress & $0.013 \pm 0.001$ & NS & $82.92 \pm 0.58$ & $>0.001$ & $5.28 \pm 0.20$ & $>0.001$ \\
\hline Chronic immobilization stress & $0.01 \pm 0.001$ & NS & $73.26 \pm 0.40$ & NS & $3.69 \pm 0.13$ & NS \\
\hline
\end{tabular}

a Abbreviation: TSH, Thyroid-Stimulating Hormone; NS, not significant.

$\mathrm{b}$ Data are presented as mean $\pm \mathrm{SD}$.

Table 2. Analysis of Data Hormone Concentration TSH, T3 and T4 in the Groups Receiving Extract Under Acute Immobilization and Chronic Immobilization Stress a, b

\begin{tabular}{lcccccc}
\hline Indexes & TSH $(\mu \mathbf{g} / \mathbf{d L})$ & P Value & T3 $(\mu \mathbf{g} / \mathbf{d L})$ & P Value & T4 $(\mu \mathbf{g} / \mathbf{d L})$ & P Value \\
\hline Receiving normal saline & $0.01 \pm 0.001$ & NS & $0.32 \pm 73.14$ & NS & $3.48 \pm 0.1$ & NS \\
Aloe vera extract & $0.006 \pm 0.001$ & NS & $71.00 \pm 0.7$ & $>0.05$ & $2.84 \pm 0.01$ & $>0.01$ \\
Acute immobilization + extract & $0.013 \pm 0.001$ & NS & $0.6 \pm 68.07$ & $>0.001$ & $3.83 \pm 0.27$ & NS \\
Chronic immobilization + extract & $0.007 \pm 0.001$ & NS & $70.98 \pm 0.7$ & $>0.05$ & $2.67 \pm 0.01$ & $>0.05$ \\
\hline
\end{tabular}

a Abbreviation: TSH, Thyroid-Stimulating Hormone NS, not significant.

b Data are presented as mean \pm SD.

Figure 1. TSH Hormone Concentration in Rats

T3, T4

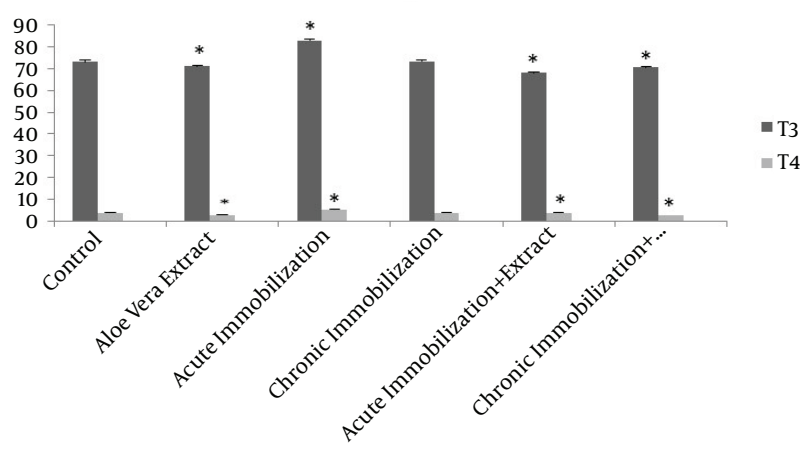

* Indicates significant difference in compared with the control group.

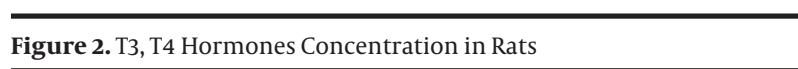

TSH

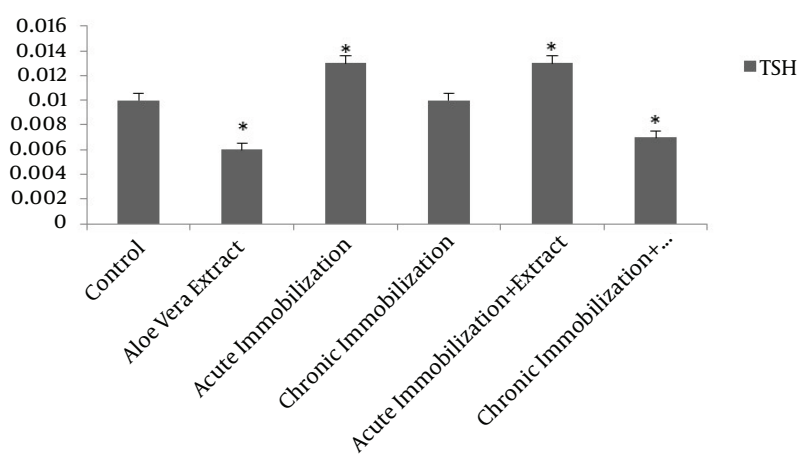

* Indicates significant difference in compared with the control group.

\section{Discussion}

The results show that acute immobilization stress increase serum levels of T3 and T4 and it has no effect on TSH. According to this study, chronic immobilization stress does not have any effect on serum level of TSH, T3 and T4. At the other hand, this study shows that the extract of Aloe vera reduces the serum level of T3 and T4. Also immobilization stress along with oral administration of aqueous extract of Aloe vera reduces T3, however, this hormone in rats under acute immobilization stress receiving normal saline have been increased.

Based on the results of this study, acute immobilization stress increases serum levels of T3 and T4 but it has no effect on TSH. In this regard, several studies show that hormones are influential in formation of stress responses (25). There are different reports stating that stress leads to increase in release of catecholamines and glucocorticoids by activities of sympathetic nerves of adrenal gland and hypothalamic-pituitary-adrenal axis (26, 27). It also increases release of excitatory amino acids in the brain (28). There are several studies showing that acute immobilization stress activate pituitary-thyroid system in rhesus monkeys (29). Other studies showed that acute immobilization stress increases the secretion of thyroid hormone $(7,13,30)$ and there are also another study showing that acute immobilization stress does not change serum level of TSH (4). Most of physiological stresses initially influence neurons aminergic and subsequently peptidergic neurons in cerebral cortex. Peptidergic neurons send branches to hypothalamus and with impact on this system, production of TRH and TSH is increased and in return T3 and T4 thyroid hormones also increase (10). However, no increase in TSH has found in this study. 
It seems that the effect of acute immobilization stress on concentration of thyroid hormones in serum is applied with influences on biological amines. In fact, it was observed that the injection of prazosin (an alpha-adrenergic block) neutralize increasing effect of acute immobilization stress (3). The changes in thyroid hormones during this study may not be enough that could not change TSH level. Another potential mechanism in explaining the increased thyroid hormones can the changes in thyroxin binding globulin (TBG) (31). On the other hand, the findings of this study also indicate that chronic immobilization stress does not have any effect on the levels of TSH, T3 and T4. Aligned with these results, there are other studies that have reported long-time stress does not influence thyroid hormones (13). However, there are other studies that show thyroid hormone levels decrease during chronic immobilization stress $(7,30)$. Other studies also argue that chronic immobilization stress decreases plasma levels of TSH and hypothalamic TRH MRNA levels in young rats $(32,33)$. In justifying the lack of effect of chronic immobilization stress on levels of hormones T3, T4 and TSH, adaptation of rats with this stress (13) may fail in changing the activity of thyroid gland during the implementation of this type of stress. Another finding of this study suggests that the aqueous extract of Aloe vera decreases serum levels of T3 and T4. In line with these results, there are other studies that show this plant has decreasing effect on the levels of $\mathrm{T} 3$ and T4 $(9,23)$. Further investigation indicated that basil leaf extract reduces serum concentrations of T4 (33). Another study found that Betel leaf extract in the lowest dose increases concentrations of $\mathrm{T} 3$ but increases concentration of $\mathrm{T} 4$ and decreases T3 concentration at higher doses (34). In this regard, the extract may not have any effect on conversion of thyroid T4 to T3 since the serum levels of T3 and T4 has reduced simultaneously. The other finding of this study shows that acute immobilization stress along with oral administration of aqueous extract of Aloe vera reduces $\mathrm{T} 3$, while this hormone has been increased in rats under acute immobilization receiving normal saline. Thus it can be said that Aloe vera extract inhibits the increasing effect of acute immobilization stress on levels of thyroid. It should be noted that not measuring free hormones is considered as the limitation of this study.

To sum up, the results of this study show that acute immobilization is increasing role in thyroid hormone secretion. But extract Aloe vera can be in habited this increase. This finding is clinically important and with more reviews in the field can be hoped that the use of these extracts in the treatment of hyperthyroidism.

\section{Acknowledgements}

This paper is adapted from a thesis Zahra Abbasi code is 171305258922011 and with the support of research deputy of Islamic Azad University, Hamedan. Here by acts appreciation and thank of efforts these dear ones.

\section{Funding/Support}

This paper was supported by the spiritual and material spheres of Islamic Azad University of Hamedan.

\section{References}

1. Bartanusz V, Aubry JM, Jezova D, Baffi J, Kiss JZ. Up-regulation of vasopressin mRNA in paraventricular hypophysiotrophic neurons after acute immobilization stress. Neuroendocrinology. 1993;58(6):625-9.

2. Armario A, Marti O, Gavalda A, Giralt M, Jolin T. Effects of chronic immobilization stress on GH and TSH secretion in the rat: response to hypothalamic regulatory factors. Psychoneuroendocri nology. 1993;18(5-6):405-13.

3. Turakulov Y, Burikhanov RB, Patkhitdinov PP, Myslitskaya AI. Influence of immobilization stress on the level of secretion of thyroid hormones. Neurosci Behav Physiol. 1994;24(6):462-4

4. Kioukia N, Bekris S, Antoniou K, Papadopoulou-Daifoti Z, Christofidis I. Effects of chronic mild stress (CMS) on thyroid hormone function in two rat strains. Psychoneuroendocrinology. 2000;25(3):247-57.

5. Nakhooda AF, Sole MI, Marliss EB. Adrenergic regulation of glucagon and insulin secretion during immobilization stress in normal and spontaneously diabetic BB rats. Am J Physiol. 1981;240(4):E373-8.

6. Maccari S, Morley-Fletcher S. Effects of prenatal restraint stress on the hypothalamus-pituitary-adrenal axis and related behavioural and neurobiological alterations. Psychoneuroendocrinology. 2007;32 Suppl 1:S10-5.

7. Langer P, Foldes O, Kvetnansky R, Culman J, Torda T, El Daher F Pituitary-thyroid function during acute immobilization stress in rats. Exp Clin Endocrinol. 1983;82(1):51-60.

8. Langer P, Vigas M, Kvetnansky R, Foldes O, Culman J. Immediate increase of thyroid hormone release during acute stress in rats: effect of biogenic amines rather than that of TSH? Acta Endocrinol (Copenh). 1983;104(4):443-9.

9. Kar A, Panda S, Bharti S. Relative efficacy of three medicinal plant extracts in the alteration of thyroid hormone concentrations in male mice. J Ethnopharmacol. 2002;81(2):281-5.

10. Watt DF, Panksepp J. Depression: An evolutionarily conserved mechanism to terminate separation distress? A review of aminergic, peptidergic, and neural network perspectives. Neuropsychoanalysis. 2009;11(1):7-51.

11. Miyata K, Ose K. Thyroid Hormone-disrupting Effects and the Amphibian Metamorphosis Assay. J Toxicol Pathol. 2012;25(1):1-9.

12. Everley G, Rosenfeld R. The nature and treatment of the stress responses.New York: Plenum Press; 1981.

13. Turakulov I, Burikhanov RB. [Role of norepinephrine in the regulation of thyroid gland functional activity in rabbits]. Probl Endokrinol (Mosk). 1993;39(4):45-8.

14. Panda S, Kar A. Withania somnifera and Bauhinia purpurea in the regulation of circulating thyroid hormone concentrations in female mice. J Ethnopharmacol. 1999;67(2):233-9.

15. Panda S, Kar A. How safe is neem extract with respect to thyroid function in male mice? Pharmacol Res. 2000;41(4):419-22.

16. Panda S, Kar A. Piperine lowers the serum concentrations of thy roid hormones, glucose and hepatic 5'D activity in adult male mice. Horm Metab Res. 2003;35(9):523-6.

17. Panda S, Kar A. Guggulu (Commiphora mukul) potentially ameliorates hypothyroidism in female mice. Phytother Res 2005;19(1):78-80.

18. Vogler BK, Ernst E. Aloe vera: a systematic review of its clinical effectiveness. Br J Gen Pract. 1999;49(447):823-8.

19. Ajabnoor MA. Effect of aloes on blood glucose levels in normal and alloxan diabetic mice. J Ethnopharmacol.1990;28(2):215-20.

20. Fujita K, Suzuki I, Ochiai J, Shinpo K, Inoue S, Saito H. Specific reaction of aloe extract with serum proteins of various animals Experientia.1978;34(4):523-4.

21. Chithra P, Sajithlal GB, Chandrakasan G. Influence of aloe vera on the healing of dermal wounds in diabetic rats. J Ethnopharmacol. 1998;59(3):195-201 
22. Nath D, Sethi N, Singh RK, Jain AK. Commonly used Indian abortifacient plants with special reference to their teratologic effects in rats. J Ethnopharmacol.1992;36(2):147-54.

23. Pigatto PD, Guzzi G. Aloe linked to thyroid dysfunction. Arch Med Res. 2005;36(5):608.

24. Sood S, Narang D, Thomas MK, Gupta YK, Maulik SK. Effect of Ocimum sanctum Linn. on cardiac changes in rats subjected to chronic restraint stress. J Ethnopharmacol. 2006;108(3):423-7.

25. Naumenko EW, Popowa KK. [Ontogenetic and genetico-evolutionary aspects of the neuroendocrine regulation of stress].Siberia: Novosibirsk; 1990.

26. Aguilera G, Kiss A, Sunar-Akbasak B. Hyperreninemic hypoaldosteronism after chronic stress in the rat. J Clin Invest. 1995;96(3):1512-9.

27. Pettersson K, Bejne B, Bjork H, Strawn WB, Bondjers G. Experimental sympathetic activation causes endothelial injury in the rabbit thoracic aorta via beta 1-adrenoceptor activation. Circ Res. 1990;67(4):1027-34.

28. Moghaddam B. Stress preferentially increases extraneuronal levels of excitatory amino acids in the prefrontal cortex: comparison to hippocampus and basal ganglia. J Neurochem.
1993;60(5):1650-7.

29. Mason JW, Mougey EH. Thyroid (plasma BEI) response to chair restraint in the monkey. Psychosom Med.1972;34(5):441-8.

30. Carmen T, RF T, Dumitrascu V. [Thyroid hormones and immobilization]. Revista Fiziologia. 2005;15(2):19-22.

31. Parra A, Villalpando S, Junco E, Urquieta B, Alatorre S, GarciaBulnes $G$. Thyroid gland function during childhood and adolescence. Changes in serum TSH, T4, T3, thyroxine-binding globulin, reverse $\mathrm{T} 3$ and free $\mathrm{T} 4$ and $\mathrm{T} 3$ concentrations. Acta Endocrinol ( $\mathrm{Co}$ penh). 1980;93(3):306-41.

32. Cizza G, Brady LS, Pacak K, Blackman MR, Gold PW, Chrousos GP. Stress-induced inhibition of the hypothalamic-pituitary-thyroid axis is attenuated in the aged Fischer $344 / \mathrm{N}$ male rat. Neuroendocrinology. 1995;62(5):506-13.

33. Cizza G, Brady LS, Esclapes ME, Blackman MR, Gold PW, Chrousos GP. Age and gender influence basal and stress-modulated hypothalamic-pituitary-thyroidal function in Fischer 344/N rats. Neuroendocrinology. 1996;64(6):440-8.

34. Panda S, Kar A. Changes in thyroid hormone concentrations after administration of ashwagandha root extract to adult male mice. J Pharm Pharmacol.1998;50(9):1065-8. 